\title{
1,3-Asymmetric Induction in Diastereoselective Allylations of Chiral $N$-Tosyl Imines
}

\author{
Anna Lo, David A. Gutierrez, Garrett Toth-Williams, James C. Fettinger and Jared T. Shaw* \\ Department of Chemistry, University of California, Davis, Davis California, 95616, United States \\ Supporting Information Placeholder
}

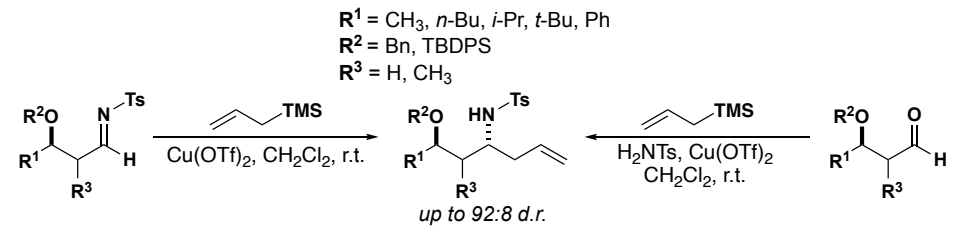

\begin{abstract}
Lewis-acid mediated allylations of $\beta$-alkoxy $N$-tosyl imines lead to 3-alkoxy homoallylic $N$-tosyl amines with anti diastereoselectivity. Diastereoselectivity and yields of reactions are comparable between two methods of Hosomi-Sakurai allylations. Observed selectivity trends and computational evidence suggest that 1,3 asymmetric induction occurs through the formation of a sixmembered ring chelate which adopts a half-chair-like conformation. The product ratios of allylations to $\beta$-alkoxy $N$-tosyl imines are dependent on conformation preferences of the chelate and stereoelectronic interactions in the transition-state structures. Debenzylation and detosylation of these allylation products result in anti 1,3-amino alcohols, a privileged motif in synthetic and natural bioactive compounds.
\end{abstract}

The use of resident stereogenic centers to control the outcome of diastereoselective reactions is a powerful strategy for the construction of complex organic molecules. Although the influence of both $\alpha$ and $\beta$ stereogenic centers on the addition of nucleophiles to aldehydes has been thoroughly studied, analogous studies of $\alpha$ - and $\beta$-substituted electron-deficient imines are sparse. We recently disclosed the first comprehensive study of $\alpha$-alkoxy imines and demonstrated high levels of either syn or anti diastereoselectivity based on the nature of the nucleophilic alkene employed. ${ }^{1}$ That study also demonstrated that the typically mono-coordinate Lewis acid $\mathrm{BF}_{3} \cdot \mathrm{OEt}_{2}$ can form a highly reactive chelate by disproportionation to $\mathrm{BF}_{2}^{+} / \mathrm{BF}_{4}^{-}$. Based on these observations, we sought to explore the factors influencing acyclic stereocontrol in $\beta$-alkoxy imines, allowing access to chiral 1,3 amino alcohols, a common motif in biologically active synthetic targets (Figure 1).,

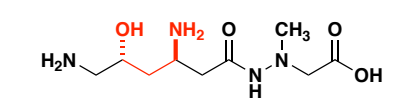

negamycin

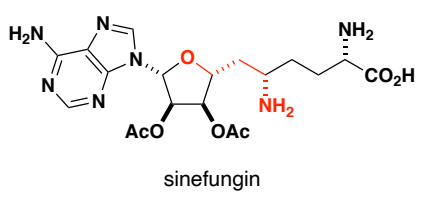

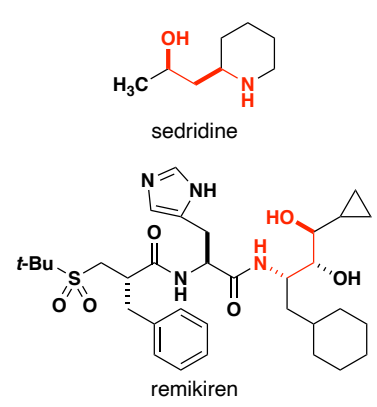

Figure 1. Examples of biologically active anti-1,3 amino alcohols.
Previously reported examples of Lewis acid mediated nucleophilic additions of $\beta$-alkoxy aldehydes show how 1,3 asymmetric induction in $\beta$-alkoxy aldimines can result in highly selective reaction outcomes. Chelateable Lewis acids used in nucleophilic additions to $\beta$-alkoxy aldehydes lead to anti-2 in high diastereomeric ratios. Reetz ${ }^{4}, \mathrm{Keck}^{5,6}$ and Heathcock ${ }^{7}$ rationalized this observed anti selectivity through the preferential approach of a nucleophile on the less hindered side of a six-membered chelate (Figure 2, A). Evans later reported comparable anti selectivity in Mukaiyama aldol additions to $\beta$ alkoxy aldehydes with $\mathrm{BF}_{3} \cdot \mathrm{OEt}_{2}$, a typically non-chelating Lewis acid. ${ }^{8}{ }^{9}$ Dipole minimization of the $\mathrm{O}-\mathrm{B}$ bond of the monocoordinated Lewis acid/substrate complex and the $\mathrm{O}-\mathrm{C} \beta$ alkoxy group were the proposed origin of the observed selectivity (Figure 2, B).

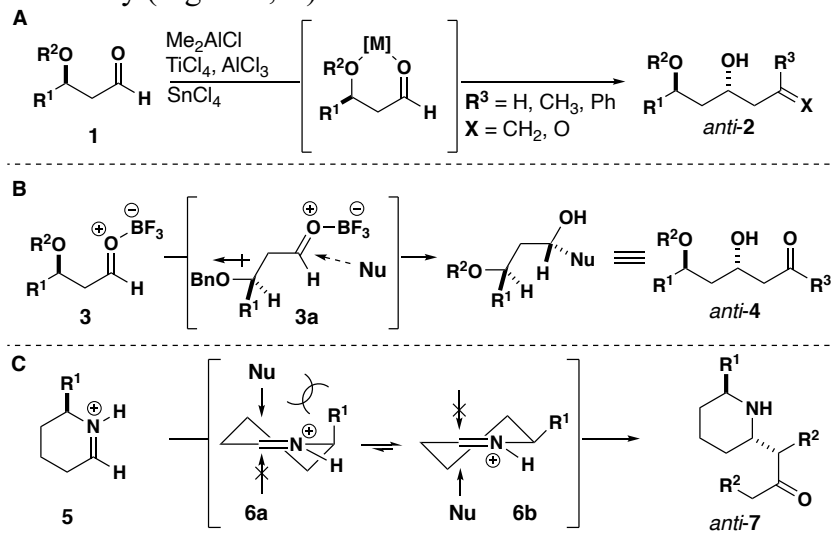

Figure 2. Lewis acid-mediated additions to $\beta$-alkoxy aldehydes. 
While six-membered chelates have been reported to form and lead to anti-products in additions to $\beta$-alkoxy aldehydes, conformational preferences of the chelate are not typically discussed. In a conformationally related reaction, Stevens uses stereoelectronic arguments to rationalize the highly selective reactions of vinyl alcohols and tetrahydropyridinium ions that adopt half-chair conformers resembling $\mathbf{6 a}$ and $\mathbf{6 b}$ (Figure 2, C). ${ }^{10}$ Anti-7 ultimately arises from nucleophilic attack on conformer $\mathbf{6 b}$ from a mode of attack that avoids formation of twist-boat products or build up of 1,3 diaxial strain. Taking this model into consideration, should a six-membered chelate form in Lewis acid mediated additions to $\beta$-alkoxy $N$-Ts imines, stereoelectronic arguments similar to Stevens' rationale and Fürst-Plattner rules may be applied to predict and control for stereochemical outcomes of half-chair six-membered chelates.

Our investigation of $\beta$-alkoxy $N$-Ts imines utilizes 1,3 asymmetric induction to access anti-1,3 amino alcohols. Furthermore, the observed diastereomeric ratios provide insight into: (1) the influence of the conformational preferences of the six-membered ring chelate (2) the origin of selectivity when $\mathrm{BF}_{3} \cdot \mathrm{OEt}_{2}$, a non-chelateable Lewis acid, is employed. The results of our investigation can help to construct a generalized model that describes the diastereomeric outcomes of additions to $\beta$-alkoxy carbon electrophiles.

We began our studies with allylations to imines 12 and $\mathbf{1 3}$ for a direct comparison to the allylations performed previously on the analogous aldehydes. Synthetic access to imines $\mathbf{1 2}$ and 13 was achieved in a couple of steps from the known analogous aldehyde precursors $\mathbf{8}$ and $\mathbf{9}$, through precipitation and isolation of amidosulfones $\mathbf{1 0}$ and $\mathbf{1 1}$ (Scheme 1). We hypothesized that should a six-membered chelate form, the anti product would predominate, such as in the case of the analogous aldehydes.

Scheme 1. Synthesis of Imines 11 and 12

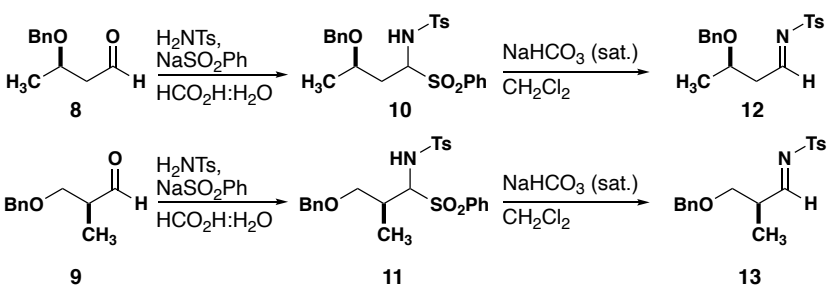

Anti-14 was the major product in allylations of imine 12 with allyltrimethylsilane regardless of Lewis acid employed (Table 1). $\mathrm{AlCl}_{3}, \mathrm{SnCl}_{4}$ and $\mathrm{Cu}(\mathrm{OTf})_{2}$ provided the best yields and

Table 1. Lewis Acid-Mediated Allylations to Imine 11

\begin{tabular}{|c|c|c|c|c|c|c|}
\hline \multicolumn{2}{|c|}{$\overbrace{12}^{\mathrm{OBn}} \overbrace{H}^{N^{-T S}}$} & \multirow{2}{*}{$\begin{array}{c}\text { [M] } \\
\text { conditions } \\
\text { Lewis-acid }\end{array}$} & \multicolumn{2}{|r|}{ Ts +} & \multicolumn{2}{|c|}{$\mathrm{H}_{s y n-14}^{\mathrm{B}_{3}}$} \\
\hline Entry & [M] & & Solvent & Temp $\left({ }^{\circ} \mathrm{C}\right)$ & anti:syn ${ }^{a}$ & yield $^{b}$ \\
\hline 1 & TMS & $\mathrm{ZnBr}_{2}$ & $\mathrm{CH}_{2} \mathrm{Cl}_{2}$ & -78 to $r t$ & $73: 27$ & $90 \%$ \\
\hline 2 & TMS & $\mathrm{Znl}_{2}$ & $\mathrm{CH}_{2} \mathrm{Cl}_{2}$ & -78 to rt & $78: 22$ & $32 \%$ \\
\hline 3 & TMS & $\mathrm{AlCl}_{3}$ & $\mathrm{CH}_{2} \mathrm{Cl}_{2}$ & -78 to $\mathrm{rt}$ & $81: 19$ & $96 \%$ \\
\hline 4 & TMS & $\mathrm{SnCl}_{4}$ & $\mathrm{CH}_{2} \mathrm{Cl}_{2}$ & -78 to rt & $80: 20$ & $92 \%$ \\
\hline 5 & TMS & $\mathrm{TiCl}_{4}{ }^{4}$ & $\mathrm{CH}_{2} \mathrm{Cl}_{2}$ & -78 to $\mathrm{rt}$ & $78: 22$ & $41 \%$ \\
\hline 6 & TMS & $\mathrm{TfOH}^{+}$ & $\mathrm{CH}_{2} \mathrm{Cl}_{2}$ & -78 to rt & $82: 18$ & $57 \%$ \\
\hline 7 & TMS & $\mathrm{BF}_{3} \cdot \mathrm{OEt}_{2}$ & $\mathrm{CH}_{2} \mathrm{Cl}_{2}$ & -78 to rt & $81: 19$ & $49 \%$ \\
\hline 8 & TMS & $\mathrm{BF}_{3} \cdot \mathrm{OEt}_{2}$ & $\mathrm{CHCl}_{3}$ & -20 & $81: 19$ & $26 \%$ \\
\hline 9 & TMS & $\mathrm{Cu}(\mathrm{OTf})_{2}$ & $\mathrm{CH}_{2} \mathrm{Cl}_{2}$ & -78 to $\mathrm{rt}$ & $79: 21$ & $72 \%$ \\
\hline 10 & TMS & $\mathrm{Cu}(\mathrm{OTf})_{2}$ & $\mathrm{PhMe}$ & -78 to -20 & $80: 20$ & $94 \%$ \\
\hline 11 & $\mathrm{BF}_{3} \mathrm{~K}$ & $\mathrm{BF}_{3} \cdot \mathrm{OEt}_{2}$ & $\mathrm{CHCl}_{3}$ & -20 & $68: 32$ & $13 \%$ \\
\hline 12 & Bpin & $\mathrm{BF}_{3} \cdot \mathrm{OEt}_{2}$ & $\mathrm{CH}_{2} \mathrm{Cl}_{2}$ & -78 to $\mathrm{rt}$ & n.d. & n.d. \\
\hline 13 & $\mathrm{SnBu}_{3}$ & $\mathrm{AlCl}_{3}$ & $\mathrm{CH}_{2} \mathrm{Cl}_{2}$ & -78 to $\mathrm{rt}$ & $76: 24$ & $60 \%$ \\
\hline $14^{c}$ & TMS & $\mathrm{Cu}(\mathrm{OTf})_{2}$ & $\mathrm{CH}_{2} \mathrm{Cl}_{2}$ & -78 to $\mathrm{rt}$ & n.d. & n.d \\
\hline
\end{tabular}

diastereomeric ratios of product for the reaction (Table 1, entries 3, 4 and 9). The anti selectivity observed for most Lewis acids can be rationalized through stereoelectronic considerations of each mode of attack on half-chair conformers 15a and 15b (Figure 3). Ruling out the trajectories of attack that lead to twist-boat products, approach of the nucleophile to the six-membered ring chelate is sterically unhindered in the case of lower energy half-chair conformer 15a while sterically hindered on the higher energy conformer $\mathbf{1 5 b}$. Stereoelectronic interactions of nucleophilic attack and conformational preferences of the chelate are reenforcing in this case and predict for the major anti-13 product observed.

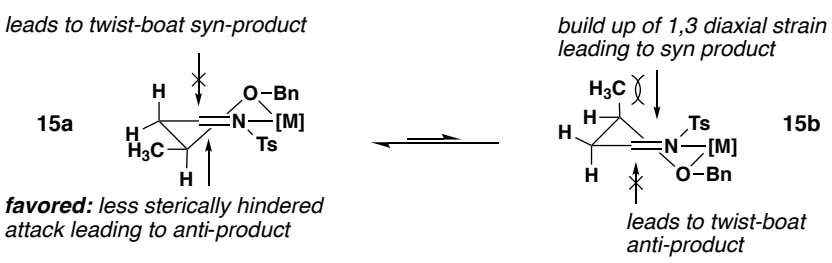

Figure 3. Four modes of nucleophilic attack on conformers 15a and $\mathbf{1 5 b}$.

The typically non-chelatable Lewis acid $\mathrm{BF}_{3} \cdot \mathrm{OEt}_{2}$ also resulted in anti selectivity (Table 1, entries 3 and 7). The major anti product observed with $\mathrm{BF}_{3} \cdot \mathrm{OEt}_{2}$ suggests that the dipolar mechanism proposed previously by Evans does not adequately explain the analogous reaction with $N$-Ts imine (Figure 4). Where $\mathrm{BF}_{3}$ would preferentially bind $Z$ to the $\mathrm{H}$ substituent on the $\mathrm{C}=\mathrm{O}$ bond of 3 (Figure 2), $\mathrm{BF}_{3}$ is forced to bind $Z$ to the alkyl substituent of imine $\mathbf{1 2}$ due to the presence of the $N$-tosyl group. To achieve the minimization of dipoles in the analogous aldehyde substrate, one would have to rotate the $\mathrm{C}-\mathrm{O}$ bond of the $\beta$-alkoxy bond $180{ }^{\circ} \mathrm{C}$ from its orientation in $\mathbf{3 a}$ (Figure 2). This would result in nucleophilic attack that avoids steric interactions with the $\beta$-methyl substituent, leading to syn-14 instead of the anti-14 product observed. (Figure 4).

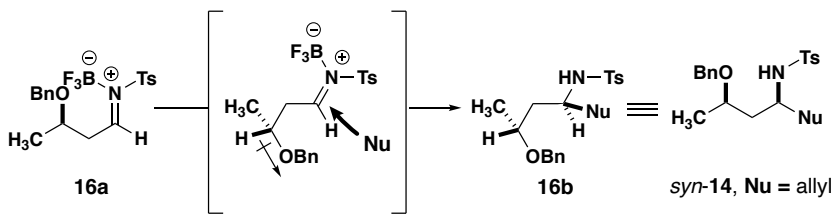

Figure 4. Consideration of dipolar effects previously proposed on $\mathrm{BF}_{3} \cdot \mathrm{OEt}_{2}$ mediated additions to imine 11 .

Imine 13 was synthesized to further probe the conformational preferences of the presumed six-membered ring chelate. If steric crowding of one face of the chelate governed selectivity alone without any conformational considerations of the

Table 2. Lewis Acid-Mediated Allylations to Imine 12

\begin{tabular}{|c|c|c|c|c|c|c|}
\hline & $\begin{array}{l}\mathrm{CH}_{3} \\
13\end{array}$ & ${ }^{[M]}$ & & & & \\
\hline Entry & [M] & Lewis-acid & Solvent & Temp $\left({ }^{\circ} \mathrm{C}\right)$ & anti:syn ${ }^{a}$ & yield $^{b}$ \\
\hline $\begin{array}{l}1 \\
2 \\
3 \\
4 \\
5 \\
6 \\
7 \\
8 \\
9 \\
10\end{array}$ & $\begin{array}{l}\text { TMS } \\
\text { TMS } \\
\text { TMS } \\
\text { TMS } \\
\text { TMS } \\
\text { TMS } \\
\text { TMS } \\
\text { TMS } \\
\text { TMS } \\
\mathrm{BF}_{3} \mathrm{~K}\end{array}$ & $\begin{array}{l}\mathrm{ZnBr}_{2} \\
\mathrm{Znl}_{2} \\
\mathrm{AlCl}_{3} \\
\mathrm{SnCl}_{4} \\
\mathrm{TiCl}_{4} \\
\mathrm{TfOH} \\
\mathrm{FeCl} \\
\mathrm{Cu}(\mathrm{OTf})_{2} \\
\mathrm{BF}_{3} \cdot \mathrm{OEt}_{2} \\
\mathrm{BF}_{3} \cdot \mathrm{OEt}_{2}\end{array}$ & $\begin{array}{l}\mathrm{CH}_{2} \mathrm{Cl}_{2} \\
\mathrm{CH}_{2} \mathrm{Cl}_{2} \\
\mathrm{CH}_{2} \mathrm{Cl}_{2} \\
\mathrm{CH}_{2} \mathrm{Cl}_{2} \\
\mathrm{CH}_{2} \mathrm{Cl}_{2} \\
\mathrm{CH}_{2} \mathrm{Cl}_{2} \\
\mathrm{CH}_{2} \mathrm{Cl}_{2} \\
\mathrm{CH}_{2} \mathrm{Cl}_{2} \\
\mathrm{CHCl}_{3} \\
\mathrm{CHCl}_{3}\end{array}$ & $\begin{array}{l}-78 \text { to rt } \\
-78 \text { to rt } \\
-78 \text { to rt } \\
-78 \text { to rt } \\
-78 \text { to rt } \\
-78 \text { to rt } \\
-78 \text { to rt } \\
-20 \\
-20 \\
-20\end{array}$ & $\begin{array}{l}68: 32 \\
29: 71 \\
82: 18 \\
71: 29 \\
75: 25 \\
50: 50 \\
56: 44 \\
60: 40 \\
50: 50 \\
52: 48\end{array}$ & $\begin{array}{c}80 \% \\
6 \% \\
93 \% \\
32 \% \\
73 \% \\
95 \% \\
52 \% \\
88 \% \\
92 \% \\
53 \%\end{array}$ \\
\hline
\end{tabular}

aantisyn diastereomeric ratios determined by intergration of ${ }^{1} \mathrm{H}$ NMR spectra of unpurified reaction mixtures. ${ }^{b}$ Yields obtained by intergration of ${ }^{1} \mathrm{H}$ NMR spectra with $1,3,5$ trimethylbenzene as the internal standard. 
electrophile, a marked improvement in selectivity should be observed in imine $\mathbf{1 3}$ when compared to imine 12. Anti-17 was formed in comparable selectivity only when $\mathrm{AlCl}_{3}$ was used as the Lewis acid (Table 2, entry 3). With all other Lewis acids, diastereomeric ratios of nucleophilic additions to imine $\mathbf{1 3}$ were, on average, lower than what was observed in allylations to imine 12 (Table 1). Reactions using $\mathrm{TfOH}, \mathrm{Cu}(\mathrm{OTf})_{2}$ and $\mathrm{BF}_{3} \bullet \mathrm{OEt}_{2}$ were all unselective (Table 2, entries 6, 8 and 9). The half-chair-like conformation invoked previously for imine $\mathbf{1 2}$ rationalizes the observed lower diastereomeric ratios for imine 13. Fürst-Plattner approach (avoidance of twist-boat products) of the nucleophile on lower energy conformer 18a is sterically unfavored as its trajectory is hindered by approach gauche to the methyl substituent (Figure 5). On the other hand, FürstPlattner approach is sterically unincumbered in conformer $\mathbf{1 8 b}$, though $\mathbf{1 8 b}$ is presumed to be higher in energy relative to that of conformer 17a due to bearing a pseudoaxial methyl group. As Fürst-Plattner rules are not reenforcing with the favored half-chair conformer of the chelate resulting from imine 13, the observed diastereomeric ratios are predictably lower.

$$
\begin{aligned}
& \text { results in gauche interaction with } \\
& \text { adjacent } \mathrm{CH}_{3} \text { group in syn-product } \\
& \text { leads to twist-boat anti-product } \\
& \text { favored: sterically unhindered attack } \\
& \text { leading to anti-product }
\end{aligned}
$$

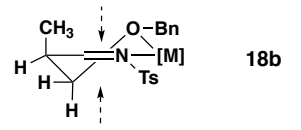

Figure 5. Consideration of Fürst-Plattner rules for additions to 18a and $\mathbf{1 8 b}$.

To explore a wider range of substrates, multicomponent reaction (MCR) conditions previously used to generate $\mathrm{N}-\mathrm{Cbz}$ imines from chiral aldehydes in situ were optimized for reactions using $N$-Ts imines (Table 3 ). ${ }^{11,}{ }^{12}$ These conditions avoid the requisite precipitation of the amido-sulfone intermediates, which is strongly substrate-dependent and does not consistently produce a solid, preventing isolation. Observed diastereomeric ratios using $\mathrm{MCR}$ conditions and $\mathrm{Cu}(\mathrm{OTf})_{2}$ matched with the diastereomeric ratios using amidosulfone derived imines and the same Lewis acid (Table 3, entry 6). Unlike the other Lewis acids used under MCR conditions, $\mathrm{Cu}(\mathrm{OTf})_{2}$ preferentially mediated addition to the imine rather

\begin{tabular}{|c|c|c|c|c|c|}
\hline Entry & Lewis-acid & Solvent & Temp $\left({ }^{\circ} \mathrm{C}\right)$ & anti:syn ${ }^{a}$ & $\%$ addition to $\mathbf{8}^{a}$ \\
\hline 1 & $\mathrm{BF}_{3} \cdot \mathrm{OEt}_{2}$ & $\mathrm{MeCN}$ & 0 & $60: 40$ & 5 \\
\hline 2 & $\mathrm{BF}_{3} \cdot \mathrm{OEt}_{2}$ & $\mathrm{CH}_{2} \mathrm{Cl}_{2}$ & -20 & $79: 21$ & 35 \\
\hline 3 & $\mathrm{AlCl}_{3}$ & $\mathrm{CH}_{2} \mathrm{Cl}_{2}$ & -20 & $68: 32$ & 19 \\
\hline 4 & $\mathrm{SnCl}_{4}$ & $\mathrm{CH}_{2} \mathrm{Cl}_{2}$ & -20 & $68: 32$ & 11 \\
\hline 5 & $\mathrm{TiCl}_{4}$ & $\mathrm{CH}_{2} \mathrm{Cl}_{2}$ & -20 & $70: 30$ & 24 \\
\hline 6 & $\mathrm{Cu}(\mathrm{OTf})_{2}$ & $\mathrm{CH}_{2} \mathrm{Cl}_{2}^{-}$ & -20 & $82: 18$ & - \\
\hline 7 & $\mathrm{Cu}(\mathrm{OTf})_{2}$ & MeCN & -20 & $60: 40$ & - \\
\hline 8 & $\mathrm{Cu}(\mathrm{OTf})_{2}$ & PhMe & -20 & $80: 20$ & - \\
\hline 9 & $\mathrm{Cu}(\mathrm{OTf})_{2}$ & $\mathrm{CH}_{2} \mathrm{Cl}_{2}$ & -20 & $80: 20$ & - \\
\hline 10 & $\mathrm{Cu}(\mathrm{OTf})_{2}$ & $\mathrm{CH}_{2} \mathrm{Cl}_{2}$ & 0 & $82: 18$ & - \\
\hline 11 & & $\mathrm{CH}_{2} \mathrm{Cl}_{2}^{-}$ & rt & $80: 20$ & - \\
\hline $12^{b}$ & \multirow{2}{*}{$\begin{array}{l}\mathrm{Cu}(\mathrm{OTf})_{2} \\
\mathrm{TfOH}\end{array}$} & $\mathrm{CH}_{2} \mathrm{Cl}_{2}$ & rt & n.d. & n.d. \\
\hline 13 & & $\mathrm{CH}_{2} \mathrm{Cl}_{2}$ & -20 & $75: 25$ & 4 \\
\hline
\end{tabular}
than the aldehyde and resulted in no detectable aldehyde addition product. However, reactions using $\mathrm{Cu}(\mathrm{OTf})_{2}$ led to no observed product in the presence of proton scavenger 2,6-ditert-butylpyridine (Table 3, entry 12). This observation accompanied by the analogous experiment performed on

Table 3. Lewis Acid-Mediated Allylations of Aldehyde 7 Using MCR Conditions

run with 2.0 equiv. of 2,6-di-tert-butylpyridine. isolated imine 12 (see Table 1, entry 14) led to the conclusion that the reaction with $\mathrm{Cu}(\mathrm{OTf})_{2}$ likely proceeds through formation of an iminium ion and observed diastereomeric ratios result from intramolecular hydrogen bonding, or protonchelation. Previous reports also corroborate proton-chelation in the case of $N$-Cbz and $N$-Ts imines. ${ }^{1,11}$

With optimized MCR conditions, aldehydes 20a-20h were converted to allylated products $\mathbf{2 1 a}-\mathbf{2 1 h}$ using MCR conditions B (Table 4). Diastereomeric ratios trended upwards with steric bulk at the $\mathrm{R}^{1}$ position. Employment of tert-butyl-diphenylsilyl (TBDPS) group at $\mathrm{R}^{2}$ resulted in complete erosion of selectivity for the reaction (Table 4, entry 1). Sterically hindered silylether substituents have less binding affinity for Lewis acids, disfavoring chelate formation. ${ }^{6}$ Aldehyde $19 \mathrm{~g}$ produced an equal mixture of diastereomeric products, presumably due to bearing methyl substituents on both sides of the preformed chelate (Table 4 , entry 7). Allylation of $\mathbf{1 9 h}$ resulted in major diastereomer anti-20h in 67:33 ratio (Table 4, entry 8), despite compounded steric bulk to one side of the chelate.

Table 4. MCR Scope

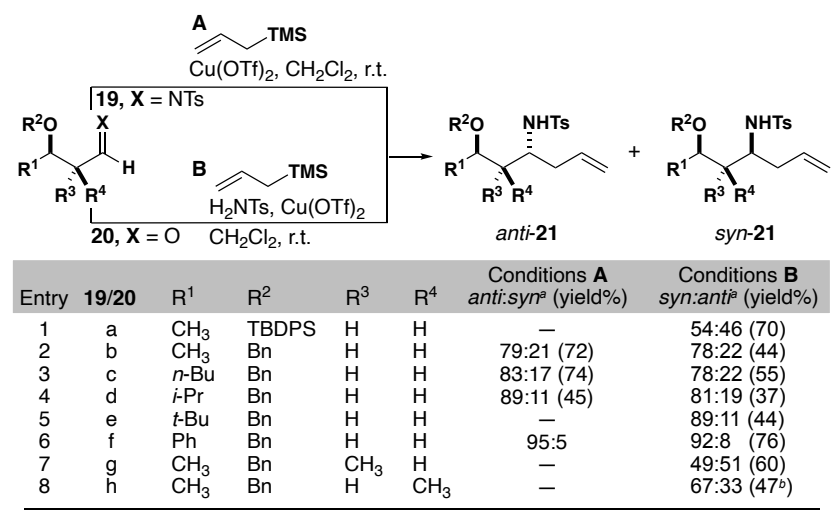

anti:syn ratios determined by intergration of ${ }^{1} \mathrm{H}$ NMR spectra of unpurified reaction mixtures. ${ }^{b}$ Yield obtained by intergration of ${ }^{1} \mathrm{H}$ NMR spectra with 1,3,5-trimethylbenzene as the interna standard.

Computational studies were conducted using Gaussian $16^{13}$ to rationalize the diastereomeric ratios of products resulting from allylations to 20. The B3LYP ${ }^{14}$ density functional with the $6-31 G(d, p)$ basis set was selected for geometry optimizations and free energy calculations for each conformer due to its demonstrated applicability to systems analogous to it. ${ }^{1}$ Calculations reveal that formation of the proton-chelate $\mathbf{2 2}$ is energetically favorable and that the chelate can adopt two halfchair-like conformations 23b and 24b (Figure 6). Assuming that the facial trajectory of nucleophilic attack is best described by Fürst-Plattner rules with the formation of twist-boat products energetically unlikely, the magnitude of diastereoselectivity observed is best represented by the overall energy difference between conformers $\mathbf{2 3 b}$ and $\mathbf{2 4 b}$ of the proton chelate.

To test this hypothesis, the relative energy differences between the two half-chairs possible of chelates 23 and 24 were

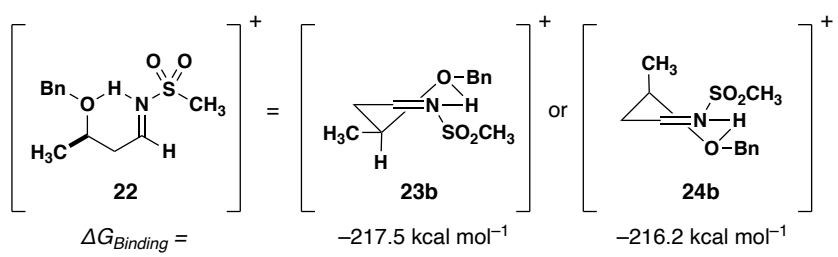

Figure 6. Calculated $\Delta \mathrm{G}_{\text {binding }}=\Delta \mathrm{G}(\mathbf{2 2})-\left(\Delta \mathrm{G}(\mathbf{1 2})+\Delta \mathrm{G}\left(\mathrm{H}^{+}\right)\right)$for proton-chelate 22. 
calculated using the same functional and basis set (Table 6). Differences in free energies of $\mathbf{2 3}$ and $\mathbf{2 4}$ were then correlated to observed diastereomeric ratios of products (Figure 7). All observed diastereomeric ratios correlated well with the magnitude of computed $\Delta \mathrm{G}(\mathbf{2 3 : 2 4})$ with the exception of tertbutyl (Table 6, entries 4). Conformer 24e bearing pseudoaxial $\mathrm{R}^{1}=t$-Bu was the computed lowest energy chelate-conformer for the tert-butyl substituted chelate. However, on this conformer, Fürst-Plattner attack would result in the build-up of significant 1,3 diaxial strain analogous to the one depicted in conformer $\mathbf{1 5 b}$ (Figure 3). So, while 24e is a competitive conformer to $23 \mathbf{e}$, $23 \mathrm{e}$ is more reactive and leads to the anti product. This would be consistent with transition state energies reflecting the ultimate product ratios described by Curtin-Hammett principles for bulkier substituents like tertbutyl. On the other hand, diastereomeric ratios observed with smaller substituents on the chelate depend more closely on the energy differences between their chelate conformers.

Table 6. Computed Free Energy Differences of 23 and 24

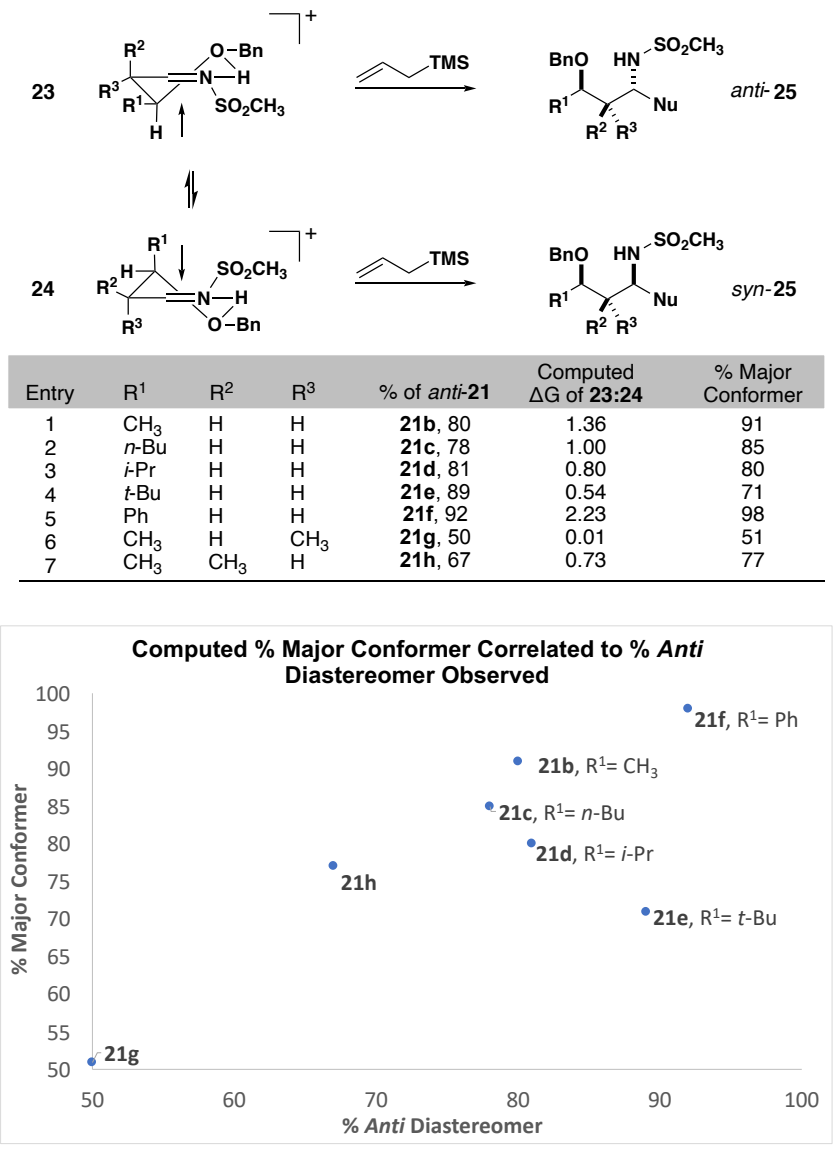

Figure 7. Graphical representation of correlation between computed \% major conformer (23 or $\mathbf{2 4}$ ) and \% anti-21 observed

To conclude, we have developed two optimized allylation reaction conditions for access to anti-1,3 amino alcohols either from $\beta$-alkoxy imine or aldehyde starting materials. Experimental and computational results show that $\mathrm{Cu}(\mathrm{OTf})_{2}$ mediated allylations of $\beta$-alkoxy imines are preceded by formation of a proton-chelate that can adopt two half-chair-like conformations. The observed diastereoselectivity of addition to the chelate is influenced by stereoelectronic interactions between half-chair chelates and nucleophile, as well as the conformational preferences of the chelate itself. The stereoelectronic considerations described herein resemble that of Fürst-Plattner rules and have been previously proposed to rationalize stereochemical outcomes of addition to tetrahydropyridinium ions. Together, we have proposed a generalizable stereoelectronic model describing nucleophilic additions to $\beta$-alkoxy imines, which will inform retrosynthetic planning of stereochemically-complex nitrogen-containing targets.

\section{ASSOCIATED CONTENT}

\section{Supporting Information}

Supporting information (experimental procedures, X-ray crystallographic data, ${ }^{1} \mathrm{H}$ and ${ }^{13} \mathrm{C}$ NMR spectra, and computational details) is available free of charge.

\section{AUTHOR INFORMATION}

\section{Corresponding Author}

*E-mail: jtshaw@ucdavis.edu

\section{ACKNOWLEDGMENT}

Research reported in this publication was supported by the National Science Foundation ( grant codes here ). J.S.F. acknowledges the computational resources provided by UCLA Institute for Digital Research and Education and the National Science Foundation through XSEDE Science Gateways Program (TG-CHE040013N). We thank Prof. Dean Tantillo for providing guidance on the computational work reported herein. We thank the National Science Foundation (Grant CHE-1531193) for the dual source Xray diffractometer.

\section{REFERENCES}

(1) Moore, L. C.; Lo, A.; Fell, J. S.; Duong, M. R.; Moreno, J. A.; Rich, B. E.; Bravo, M.; Fettinger, J. C.; Souza, L. W.; Olmstead, M. M.; Houk, K. N.; Shaw, J. T., Chem. Eur. J. Soc. 2019, 25 (52), 12214 12220 .

(2) Lait, S. M.; Rankic, D. A.; Keay, B. A., Chem. Rev. 2007, 107 (3), 767-796.

(3) Palchykov, V. A.; Gaponov, A. A., Chapter Four - 1,3-Amino alcohols and their phenol analogs in heterocyclization reactions. In Adv. Heterocycl. Chem., Scriven, E. F. V.; Ramsden, C. A., Eds. Academic Press: 2020; Vol. 131, pp 285-350.

(4) Reetz, M. T.; Jung, A., J. Am. Chem. Soc. 1983, 105 (14), 48334835 .

(5) Keck, G. E.; Castellino, S., J. Am. Chem. Soc. 1986, 108 (13), 3847-3849.

(6) Keck, G. E.; Castellino, S.; Wiley, M. R., J. Org. Chem. 1986, 51 (26), 5478-5480.

(7) Kiyooka, S.-i.; Heathcock, C. H., Tetrahedron Lett. 1983, 24 (44), 4765-4768

(8) Evans, D. A.; Duffy, J. L.; Dart, M. J., Tetrahedron Lett. 1994, 35 (46), 8537-8540.

(9) Evans, D. A.; Dart, M. J.; Duffy, J. L.; Yang, M. G., J. Am. Chem. Soc. 1996, 118 (18), 4322-4343.

(10) Evans, D. A.; Allison, B. D.; Yang, M. G.; Masse, C. E., J. Am. Chem. Soc. 2001, 123 (44), 10840-10852.

(11) Ella-Menye, J.-R.; Dobbs, W.; Billet, M.; Klotz, P.; Mann, A., Tetrahedron Lett. 2005, 46 (11), 1897-1900.

(12) Pasunooti, K. K.; Leow, M. L.; Vedachalam, S.; Gorityala, B. K.; Liu, X.-W., Tetrahedron Lett. 2009, 50 (24), 2979-2981.

(13) Frisch, M. J.; Trucks, G. W.; Schlegel, H. B.; Scuseria, G. E.; Robb, M. A.; Cheeseman, J. R.; Scalmani, G.; Barone, V.; Petersson, G. A.; Nakatsuji, H.; Li, X.; Caricato, M.; Marenich, A. V.; Bloino, J.; Janesko, B. G.; Gomperts, R.; Mennucci, B.; Hratchian, H. P.; 
Ortiz, J. V.; Izmaylov, A. F.; Sonnenberg, J. L.; Williams; Ding, F.; Lipparini, F.; Egidi, F.; Goings, J.; Peng, B.; Petrone, A.; Henderson, T.; Ranasinghe, D.; Zakrzewski, V. G.; Gao, J.; Rega, N.; Zheng, G.; Liang, W.; Hada, M.; Ehara, M.; Toyota, K.; Fukuda, R.; Hasegawa, J.; Ishida, M.; Nakajima, T.; Honda, Y.; Kitao, O.; Nakai, H.; Vreven, T.; Throssell, K.; Montgomery Jr., J. A.; Peralta, J. E.; Ogliaro, F.; Bearpark, M. J.; Heyd, J. J.; Brothers, E. N.; Kudin, K. N.; Staroverov, V. N.; Keith, T. A.; Kobayashi, R.; Normand, J.; Raghavachari, K.; Rendell, A. P.; Burant, J. C.; Iyengar, S. S.; Tomasi, J.; Cossi, M.; Millam, J. M.; Klene, M.; Adamo, C.; Cammi, R.; Ochterski, J. W.; Martin, R. L.; Morokuma, K.; Farkas, O.; Foresman, J. B.; Fox, D. J. Gaussian 16 Rev. C.01, Wallingford, CT, 2016. 